\title{
To Compare the Results of Endoscopic Sinus Surgery with and without Microdebrider in Patients of Nasal Polyposis
}

\author{
${ }^{1}$ Vikas Kakkar, ${ }^{2}$ Chandni Sharma, ${ }^{3}$ Poonam Singla, ${ }^{4}$ Ankit Gulati, ${ }^{5}$ Surender Singh, ${ }^{6}$ Priya Malik
}

\begin{abstract}
Objective: To compare the results in patients of nasal polyposis undergoing endoscopic sinus surgery with or without the use of microdebrider.
\end{abstract}

Materials and methods: The study was conducted on 40 patients of either sex in age group 15 to 60 years with nasal polyposis. They were divided into two groups (20 each), in group A microdebrider was used and in group B it was not used. Symp-tom scoring of each patient was done on the basis of nasal blockage, headache, olfactory disturbance, nasal discharge and trigeminal pressure pain. Similar scoring was followed for diagnostic endoscopy in which the scoring was done on the basis of extent of polyps, edema of middle turbinate and secretions in middle meatus. Both the left and right sides were examined and scored separately.

Results: The symptom and endoscopy scores were significantly higher ( $p<0.02$ and $<0.0001$ respectively) in group B post-operatively on 14th day and after 3 months as compared to group A.

Conclusion: Microdebrider assisted endoscopic sinus surgery gives better results.

Keywords: Nasal polyposis, Endoscopic sinus surgery, Microdebrider.

How to cite this article: Kakkar V, Sharma C, Singla P, Gulati A, Singh S, Malik P. To Compare the Results of Endoscopic Sinus Surgery with and without Microdebrider in Patients of Nasal Polyposis. Clin Rhinol An Int J 2014;7(2):61-63.

Source of support: Nil

Conflict of interest: None declared

\section{INTRODUCTION}

Nasal polyposis is a common inflammatory pathology of the paranasal mucosa, leading to the protrusion of polyps into the nasal cavity. Nasal polyposis affects nearly $4 \%$ of the total population in western countries, and presents a real challenge to the physician because of its severity, chronicity

\footnotetext{
${ }^{1}$ Senior Professor, ${ }^{2,3}$ Ex-Resident, ${ }^{4-6}$ Resident

${ }^{1-6}$ Department of Otorhinolaryngology, Pt BD Sharma University of Health Sciences, Rohtak, Haryana, India

Corresponding Author: Chandni Sharma, Ex-Resident Department of Otorhinolaryngology, Pt BD Sharma University of Health Sciences, Rohtak, Haryana, India, e-mail: drchandni13ent@gmail.com
}

and recurrence rate. ${ }^{1,2}$ It can be primary or may occur as a symptom of various syndromes, including asthma and aspirin idiosyncrasy. ${ }^{3}$ The aims of treatment are to relieve nasal symptoms, restore nasal breathing and olfaction and prevent recurrence. $^{4}$

In majority of the patients the polyps arise from anterior ethmoids. The most frequent sites of origin are the contact areas of uncinate process and middle turbinate and ethmoidal infundibulum. In almost two-third of patients polyps also originate from anterior aspect of ethmoidal bulla, where they obstruct the hiatus semilunaris. ${ }^{5}$

The treatment of nasal polyposis can be either medical or surgical. Surgery is functional endoscopic surgery which is carried out using standard instruments with or without microdebrider. ${ }^{6}$ The powered sinus instruments entered the landscape many decades ago with the introduction of the microdebrider. Since then, several other powered tools, such as the endoscopic drill (equipped with suction-irrigation), coblator and the ultrasonic aspirator have been used during endoscopic sinus as well as skull base surgery. ${ }^{7}$ The original design of the microdebrider was patented by Urban in 1969 as a 'vacuum rotator dissector'. The microdebrider is a cylindrical and electrically powered shaver. ${ }^{8}$ Microdebrider preserves nasal mucosa with limited blood loss. Simultaneous continuous suction at the operative site has marked benefit as functions of sinuses and nasal cavities are restored to normal in a very short time after surgery. ${ }^{9}$ Healing process is good without obstruction and crusting. ${ }^{10}$ Further biopsy can be taken during surgery for histopathological examination using in-line suction trap on standard microdebrider. The primary drawback of microdebrider over conventional tools continues to be its higher cost associated with its use, which include the initial capital expenditure for the system and ongoing cost of disposable blades, bits and tips. ${ }^{7}$

\section{MATERIALS AND METHODS}

This prospective study was conducted in the department of Otorhinolaryngology, Pt BD Sharma University of Health Sciences, PGIMS, Rohtak, on 40 patients of either sex in age group 15 to 60 years with nasal polyposis. Symptom scoring of each patient was done on the basis of nasal blockage, headache, olfactory disturbance, nasal discharge and trigeminal pressure pain. Each symptom was assessed semi- 
quantitatively and scores of 0,1 and 2 were given on the basis of severity of each symptom to each patient. A minimum possible score of 0 and a maximum score of 10 was thus obtained for each patient in both groups. Similar scoring was followed for diagnostic endoscopy in which the scoring was done on the basis of extent of polyps, edema of middle turbinate and secretions in middle meatus. Both sides were examined and scored separately. A minimum possible score of 0 and a maximum score of 12 was thus obtained for each patient. Patients were divided into two groups. In group A, patients underwent surgery with conventional instruments along with microdebrider and in group B, patients underwent surgery with conventional instruments only. Patients underwent functional endoscopic sinus surgery according to the technique described by Stammberger. ${ }^{11}$

Patients were prescribed tablet amoxyclav (625 mg, BD), tablet levocetrizine and ambroxol (1 tablet BD) and steroids (both orally and topically). Orally methylprednisolone in dose of $0.5 \mathrm{mg} / \mathrm{kg} / \mathrm{day}$ for 1 week was given and then tapered next week. Topically fluticasone propionate two puffs twice a day in each nostril was given for 3 months. Antibiotic was continued for 2 weeks postoperatively. Assessment was done 1 week, 2 weeks and 3 months postoperatively. Statistical analysis was done using two-tailed unpaired student's t-test. p-values less than 0.05 were considered to be significant.

\section{RESULTS}

Age of patients in both age groups was in the range of 15 to 60 years. There were 10 males $(50 \%)$ and 10 females $(50 \%)$ in group A and eight males (40\%) and 12 females $(60 \%)$ in group B.

The symptom score was assessed pre and postoperatively after 7 days, 14 days and 3 months in all cases of both the groups. The preoperative symptom scores in group A and $B$ were significantly $(\mathrm{p}<0.0001)$ higher compared to the symptom score assessed postoperatively after 7 days, 14 days and 3 months. The symptom scores in group B evaluated postoperatively after 14 days and 3 months were significantly higher when compared to similar assessment done after 14 days and 3 months in group $\mathrm{A}(\mathrm{p}<0.02)$, but no statistical difference was seen in symptom scores assessed after 7 days in both groups $(p=0.17)$.

The endoscopy score was assessed pre and postoperatively after 7 days, 14 days and 3 months in both groups. The preoperative scores in group A and B were not statistically different $(p=0.2)$. The endoscopy score preoperatively in group A was $9.35 \pm 0.30$ and, in group B, was $9.60 \pm 0.34$. The preoperative scores in groups $\mathrm{A}$ and $\mathrm{B}$ were not statistically different. The preoperative scores in groups A and B were significantly $(p<0.0001)$ higher when compared to the postoperative scores after 7 days, 14 days and 3 months. The postoperative endoscopy scores in group A were $4.05 \pm 0.29$ after 7 days, $3.10 \pm 0.38$ after 14 days and $2.75 \pm 0.61$ after 3 months. The postoperative endoscopy scores in group B after 7 days, 14 days and 3 months were $4.10 \pm 0.43,4.20$ \pm 0.45 and $6.15 \pm 0.58$ respectively. The endoscopy scores in group B evaluated postoperatively after 3 months were significantly higher $(p<0.0001)$ when compared to similar assessment done after 3 months in group A but no statistical difference was seen in symptom scores assessed after 7 days and 14 days in between both groups.

One (5\%) case was found to have postoperative adhesion in group A while 4 (20\%) cases in group B were found to have the same at the end of 3 months postoperatively which was significantly more.

\section{DISCUSSION}

For most patients with nasal polyposis definitive sinus surgery is essential to achieve sufficient ventilation and drainage of affected sinuses. To provide for drainage of sinuses, mucosal preservation is essential, or when severely damaged, limited removal of pathological changes should be attempted. ${ }^{12-14}$ Rapid postoperative recovery of mucociliary function depends on mucosal and ciliary regeneration. ${ }^{14}$ Aggressive removal of mucosa leads to scar formation and resultant synechiae may occur between opposing damaged surfaces. Standard instruments usually tear tissue and strip mucous membranes. Consequently, this leads to increased bleeding with decreased visibility and undesirable frequency of complications and scarring. ${ }^{15,16}$

With the use of microdebrider healing time is accelerated, which is attributed to decreased mucosal stripping and minimal exposure of bone. Due to continuous suction at the site of surgical resection it results in clearer surgical field. ${ }^{8}$

A study on 40 patients of endoscopic sinus surgery performed with microdebrider by Bernstein et al showed rapid mucosal healing, minimal crust formation and a low incidence of synechiae formation. ${ }^{17} \mathrm{In}$ a retrospective study of Krause and Christmas, it was observed that the use of microdebrider resulted in faster healing with less crusting, decreased bleeding, decreased synechiae formation, decreased lateralization of middle turbinate and decreased ostial reocclusion. ${ }^{18}$ The same was observed in the present study.

In the present study, preoperative endoscopy score in group A was $9.35 \pm 0.30$ and in group B was $9.60 \pm 0.34$. No statistically significant differerence in scores was seen in both the groups making them comparable before surgery. The postoperative endoscopy scores in group A were $4.05 \pm$ 0.29 after 7 days, $3.10 \pm 0.38$ after 14 days and $2.75 \pm 0.61$ 
after 3 months. The postoperative endoscopy scores in group B after 7 days, 14 days and 3 months were $4.10 \pm 0.43,4.20 \pm$ 0.45 and $6.15 \pm 0.58$ respectively. The endoscopy scores in group B evaluated postoperatively after 3 months were significantly higher $(\mathrm{p}<0.0001)$ when compared to similar assessment done after 3 months in group A indicating better results with microdebrider.

Adhesion formation at the end of 3 months was more in patients of group B when compared to patients in group A, $20 \%$ patients in group B had scar and adhesion formation. Stankiewicz reported adhesion in $6.7 \%$ of 90 patients operated with conventional instruments. ${ }^{19}$ Similar results were obtained by Jacobs et $\mathrm{al}^{20}$ in $13 \%$ patients, Devis et $\mathrm{al}^{21}$ in $7.7 \%$, Kennedy ${ }^{22}$ in $4 \%$ and Lazar et $\mathrm{al}^{23}$ in $27 \%$ of patients respectively. In group A, incidence of scarring and adhesion formation was $5 \%$ which was lower to the incidence seen in group B. Bernstein et al found an incidence of $1.3 \%$ adhesion formation with microdebrider which is considerably lower than the incidence obtained by other researchers doing studies on conventional instruments. ${ }^{17}$ This can be explained by the fact that when bone surface is exposed, edematous proliferation of granulation occurs. Later on, this granulation changes into scar tissue which results in adhesion formation. Regeneration of mucosa is significantly delayed postoperatively and most of the epithelial cells regenerating postoperatively on scar tissue are nonciliated resulting in impaired drainage. When only mucosa is damaged using microdebrider, the remaining diseased submucosal tissue normalizes in a relatively short time with improvement in accompanying inflammation resulting in rapid healing. ${ }^{17}$

In conclusion, microdebrider seems to hold a definitive edge over the conventional instruments in patients of bilateral nasal polyposis with more improvement of symptoms and development of fewer complications.

\section{REFERENCES}

1. Bachert G, Watelet JB, Beveart P, Van Cauwenberge P. Pharmocological management of nasal polyposis. Drugs 2005;66: 1537-1552.

2. Benninger MS. Adult chronic rhinosinusitis: definitions, diagnosis, epidemiology and pathophysiology. Otolaryngol Head Neck Surg 2003;129S:S1-S32.

3. Mygind N, Lildholdt T. Nasal polyposis. An inflammatory disease and its treatment. Copenhagen: Munksgaard; 1997. p. 1-183.

4. Dalzeil K, Stein K, Round A, Garside R, Royle P. Systematic review of endoscopic sinus surgery for nasal polyps. Health Tech Ass 2003;7:1-170.
5. Stammberger H. Functional endoscopic sinus surgery: special endoscopic anatomy of lateral nasal wall and ethmoid sinus. In: Hawke M, editor. Philadelphia BC Deker; 1991. p. 49-87.

6. Neils M, Valerie JL. Nasal polyposis. In: Gleeson M, Browning GG, Burton MJ, Clarke R, Hibbert J, Jone NS, et al, editors. Scott Brown's Otorhinolaryngology, Head and Neck Surgery. 7th ed. Great Britain: Hodder Arnold; 2008. p. 1549-1557.

7. Bruggers S, Sindwani R. Evolving trends in powered endoscopic sinus surgery. Otolaryngol Clin North Am 2009;42: 789-798.

8. Gross CW, Becker DG. Powered instrumentation in endoscopic sinus surgery. Op Tech Otolaryngol- Head Neck Surg 1996; 7:236-241.

9. Dalke R, Burduk P, Mierzwinski J, Kazmierczak H. Rotation suction knife (shaver) as otolaryngology surgery. Otolaryngol Pol 2006;60:37-40.

10. Ceylan K. Impact of microdebrider in surgical treatment of nasal polyposis in terms of health related quality of life and objective findings: a comparative randomized single blinded clinical study. KBB-Forum 2007;6:60-65.

11. Stammberger H, Posawetz W. Functional endoscopic sinus surgery: concept, indication and the results of the Masserklinger technique. Eur Arch Otorhinolaryngol 1990;247:63-76.

12. Moriyama H, Ozawa M, Honda Y. Endoscopic endonasal sinus surgery. Approaches and postoperative evaluation. Rhinology 1991;29:93-98.

13. Moriyama H, Yanagi K, Ohtori N, Fukami M. Evaluation of endoscopic sinus surgery for chronic sinusitis: postoperative erythromycin therapy. Rhinology 1995;33:166-170.

14. Moriyama H, Yanagi K, Ohtori N, et al. Healing process of sinus mucosa after endoscopic sinus surgery. Am J Rhinol 1996;10: 61-66.

15. Gross WE. Soft tissue shavers in functional endoscopic sinus surgery (standard technique). Otolaryngol Clin North Am 1997; 30:433-441.

16. Christmas DA, Krouse JH. Powered instrumentation in endoscopic sinus surgery I: surgical technique. Ear Nose Throat J 1996;75:33-36.

17. Bernstein JM, Lebowitz RA, Jacobs JB. Initial report on post-operative healing after endoscopic sinus surgery with microdebrider. Otolaryngol Head Neck Surg 1998;118:800-803.

18. Krouse JH, Christmas DA. Powered instrumentation in endoscopic sinus surgery II: surgical technique. Ear Nose Throat J 1996;75:39-43.

19. Stankiewicz JA. Complications of intranasal endoscopic ethmoidectomy. Laryngoscope 1987;97:1270-1273.

20. Jacobs JB, Gittelman P, Holiday R. Endoscopic sinus surgery for ostiomeatal disease. Am J Rhinol 1990;4:41-43.

21. Davis WE, Templer JW, Lamear WR. Patency rate of endoscopic middle meatus antrostomy. Laryngoscope 1991;101: 416-420.

22. Kennedy DW. Prognostic factors, outcomes and staging in ethmoid sinus surgery. Laryngoscope 1992;102(Suppl 57):1-18.

23. Lazar RH, Younis RT, Long TE. Functional endonasal sinus surgery in adults and children. Laryngoscope 1993;103: $1-5$. 